\title{
Response Times and Patient Satisfaction in Emergency Room at Anutapura General Hospital, City of Palu
}

\author{
Diah Mutiarasari ${ }^{\star}, \dagger, 1$, Miranti $^{2}$ Indah Puspasari Kiay Demak ${ }^{3}$ \\ ${ }^{1}$ Department of Public Health Faculty of Medicine, Tadulako University, Tadulako University Hospital Central Sulawesi, Indonesia ${ }^{2} 1$ \\ ${ }_{3}^{2}$ Department of Public Health Faculty of Medicine, Tadulako University, Tadulako University Hospital Central Sulawesi, Indonesia ${ }^{3} 1$ \\ ${ }^{3}$ Department of Public Health Faculty of Medicine, Tadulako University, Tadulako University Hospital Central Sulawesi, Indonesia
}

DDOI: https://doi.org/10.15520/jcmro.v2i05.165

Accepted 28-05-2019; Received 15-05-2019; Publish Online 29-05-2019

Reviewed By: DR.
JESTONI D.
MANIAGO
Department:
Reviewer/ CMRO

\begin{abstract}
Emergency Room (ER) is a unit of a hospital that provides early containment procedures for emergency patients to saving lives and preventing further disability. Things that determine the success of the rescue of patients with response time. Response time is the speed of patients treated since patients came to receive medical service in a matter of minutes. Response time is good for the patient in accordance with the minimum service standards on the Minister of Health of the Republic of Indonesia number 129 of 2008 is $<5$ minutes. Response time is one indicator of hospital quality services is an indicator of the process to achieve results indicators. Patient satisfaction is an evaluative response, emotional related to the quality of existing services in hospitals and patient expectations of the services. This study aimed to analyze the relationship between the physician response times to the satisfaction of the patient's in the Emergency Room at Anutapura General Hospital Palu. Using observational method with cross sectional approach. Non-probability sampling technique is consecutive sampling. Total sample of 50 respondents in accordance with the inclusion and exclusion criteria. The research instrument used watches and questionnaires. Data Analyze with chi square test and Wilcoxon test.

The results showed that the variables of gender, age, education and occupation there was no correlation with the level of patient satisfaction. This is evident from the value of $p>0.05$ for all variables. To test the variable level of satisfaction and response time there is a relationship. This is evidenced by the $p$-value is less than the alpha (0.023> 0.05). Physician response times are very important in the treatment of emergency patients and it will certainly affect the quality of life and patient satisfaction, including suppression of the incidence of mortality and morbidity of patients in the ER.
\end{abstract}

Key words: Response time-patient satisfaction-emergency room

\section{INTRODUCTION:}

The hospital is an institution engaged in health care services are organized with the framework of the health care system of quality control and cost control resulting in an effective and efficient services in complete personal health services that provides inpatient, outpatient, and emergency services. In essence, the hospital serves as a place of healing diseases and health recovery, function intended meaning of responsibility which should be the government responsibil-

\footnotetext{
* Corresponding author

$\dagger$ Email: diah.mutiarasari@untad.ac.id
}

ity to improve of society well-being. Hospitals have the task of providing personal health services perfectly. [1] [2] Emergency Room (ER) is one part of hospital services, which is the main gate of the emergency department admissions and perform actions based on triage of patients. [3]

Based of health Ministerial Decree number 129 of 2008 on Minimum Service Standards Hospital, a response time of doctor emergency services explained that the speed of doctor service in the ER is the length of patients treated since coming to receive medical service in a matter of minutes. Response time has a standard maximum of 5 minutes in each case and to the emergency services at least the standard of patient satisfaction reached $70 \%$. Patient satisfac- 


\section{Response Times and Patient Satisfaction in Emergency Room at Anutapura General Hospital, City of Palu

tion is a good feeling of them that appear after comparing the expected with the hospital services obtained. $[4,5]$

Anutapura General Hospital is one of the government referral hospitals with accredited B as a teaching hospital in the city of Palu in Central Sulawesi province providing complete health services to the community. Based on preliminary studies, the data of patient visits the emergency room at the hospital in 2016 as many as 38.063 patients, where the average visits per day is 104 patients with surgical patients amounted to 5.283, non-surgical patients amounted to 20.410 , obstetrics patients amounted to 4,081 and pediatric patients amounted to 8289. In addition, were also found the evaluating of response time physician to patient satisfaction rate in Emergency Room at Anutapura Hospital has not been done. Therefore, researchers would be conducting study to analysis the relationship of physician response time and patient satisfaction in ER at Anutapura hospital, so ER better prepared to implement the Minimum Service Standards in terms of response time medical treatment which would affect the level of patient satisfaction.

\section{METHODS:}

The study used observational method with cross sectional approach. The sampling technique used is non-probability sampling is consecutive sampling. Samples are patients admitted to the ER Anutapura Hospital Palu, non referral patient with yellow triage category in the ER of Anutapura Hospital totaling 50 patient. The study was conducted in 2018. The research instrument used watches and questionnaires. The validity and reliability of the questionnaire was conducted in ER of Undata Hospita Palu in February 2018 on 30 respondents. Results validity and reliability of the questionnaire can be seen in Table 1 :

Table 1. Results of Validation Test Questionnaire

\begin{tabular}{|c|c|c|c|}
\hline Quaestion & $\begin{array}{l}\text { R value of } \\
\text { Product } \\
\text { Moment of } \\
\text { Sample } 30 \\
\text { and } 10 \% \\
\text { Significant } \\
\text { Level }\end{array}$ & $\begin{array}{l}\text { Pearson } \\
\text { Correlation } \\
\text { Value }\end{array}$ & Result \\
\hline 1 & 0,463 & 0,654 & Valid \\
\hline 2 & 0,463 & 0,597 & Valid \\
\hline 3 & 0,463 & 0,759 & Valid \\
\hline 4 & 0,463 & 0,749 & Valid \\
\hline 5 & 0,463 & 0,735 & Valid \\
\hline 6 & 0,463 & 0,714 & Valid \\
\hline 7 & 0,463 & 0,787 & Valid \\
\hline 8 & 0,463 & 0,807 & Valid \\
\hline 9 & 0,463 & 0,771 & Valid \\
\hline 10 & 0,463 & 0,862 & Valid \\
\hline 11 & 0,463 & 0,722 & Valid \\
\hline 12 & 0,463 & 0,697 & Valid \\
\hline 13 & 0,463 & 0,830 & Valid \\
\hline 14 & 0,463 & 0,765 & Valid \\
\hline 15 & 0,463 & 0,625 & Valid \\
\hline
\end{tabular}

In order to reliably test the researchers used a questionnaire Cronbach Alpha formula, in which the reliability of the instrument count value compared to the value of a reliable table. Instrument reliability calculated value compared to the value of a reliable table, if the result $\alpha \geq 0.9$ is meaning a very good results. Cronbach's alpha that questionnaires used reliable. Patient satisfaction questionnaire reliability value is 0.937 , meaning that the internal consistency of all instruments in this questionnaire is very good.

Table 2. Characteristics of Research Subjects

\begin{tabular}{lll}
\hline Characteristics & Frequency & Percentage (\%) \\
Gender & & \\
Male & 21 & 42 \\
Female & 29 & 58 \\
Ages & & \\
$<17$ Years & 14 & 28 \\
$17-25$ Years & 4 & 8 \\
$26-35$ Years & 10 & 20 \\
$36-45$ Years & 5 & 10 \\
$46-55$ Years & 5 & 10 \\
$56-65$ Years & 5 & 10 \\
$>65$ Years & 7 & 14 \\
Occupation & & \\
Civil Servant & 7 & 14 \\
Entrepreneur & 7 & 14 \\
Farmer & 2 & 4 \\
Pensionary & 8 & 16 \\
Erratic jobs & 26 & 52 \\
Education & & \\
None & 8 & 16 \\
Elementary & 6 & 12 \\
Junior Hihg School & 6 & 12 \\
Senior Hihg School & 16 & 32 \\
Diploma & 4 & 8 \\
Bachelor & 10 & 20 \\
\hline
\end{tabular}

\section{RESULT:}

\section{Characteristics of Respondents:}

Based on Table 2, the number of respondents based on sex a men and women respectively, are 21 people (42\%) and 29 people $(58 \%)$. The most age ranges, at $<17$ years of 14 people (28\%). Respondents occupation is varies, most of erratic jobs as many as $26(52 \%)$, which consists of housewives, students, and it does not work. Most respondents with high school education levels of 16 people $(32 \%)$.

Data Analysis:

A univariate analysis performed to describe of the frequency distribution based on the characteristics of patient satisfaction and response times are acceptived. The description of frequency distribution can be seen in Figure 1 to Figure 5:

In Figure 1, it appears that female patients tended more satisfied with the service in the ER than male. In Figure 2, showed that the highest number of patients are in the age range $<17$ years, and most of them were satisfied with the service in the ER, which amounted to $24 \%$. While the presentation patients are not satisfied amounted to $4 \%$. In Figure 3 , it appears that $44 \%$ of patients with erratic jobs were 


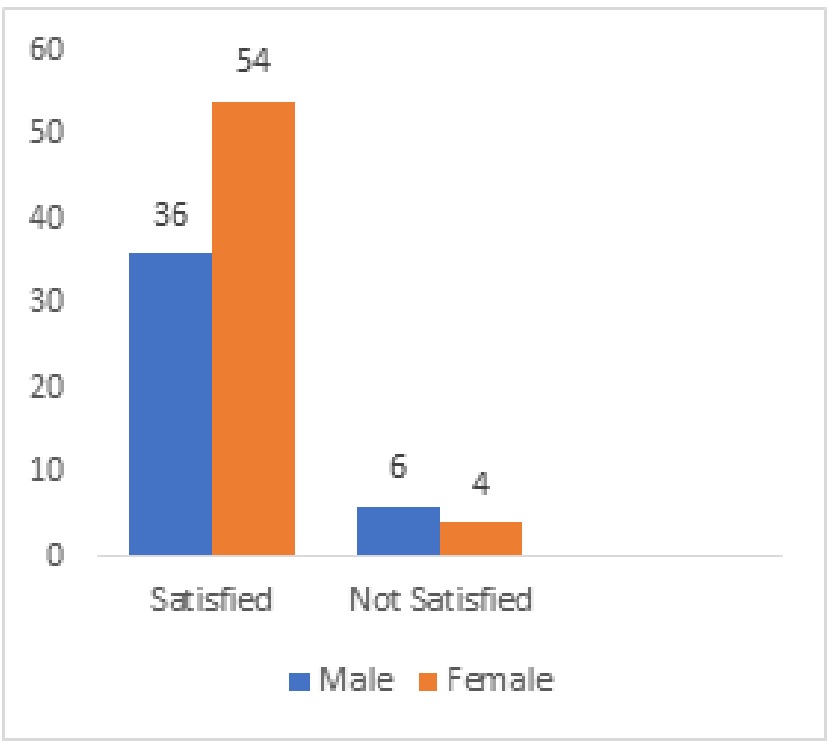

Figure 1. Presentation of satisfaction levels y gender

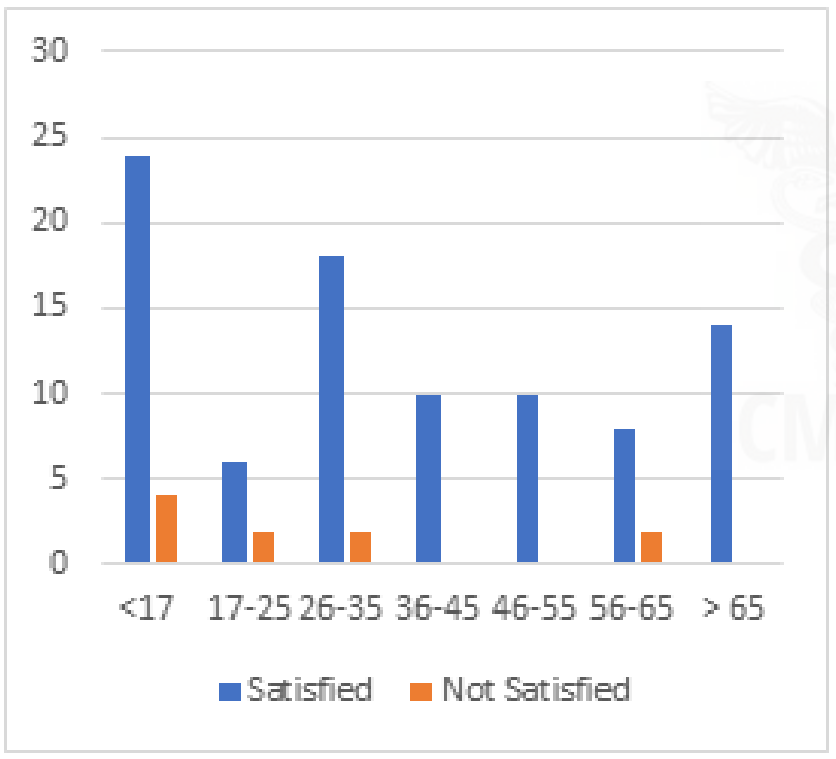

Figure 2. Percentage of satisfaction level by age group

satisfied with the service in the ER, while $8 \%$ are dissatisfied. For the work of civil servants, farmers and retirees, all patients were satisfied with the service. In Figure 4 , the patient with the highest satisfaction level at $30 \%$ of high school education. Of each level of education, an average of $2 \%$ patients were dissatisfied with the service in the ER, except at the level of bachelor, all patients were satisfied. Based on Figure 5, described that the patients served quickly more satisfied than patients who later addressed. Of all the subjects, as much as $88 \%$ was response quickly and satisfied with the service, while $6 \%$ were satisfied even though the response time is slow. While there are still $2 \%$ of patient who were dissatisfied with the service in the ER despite its relatively fast response time, and $4 \%$ of patients are not satisfied that it is slow response.

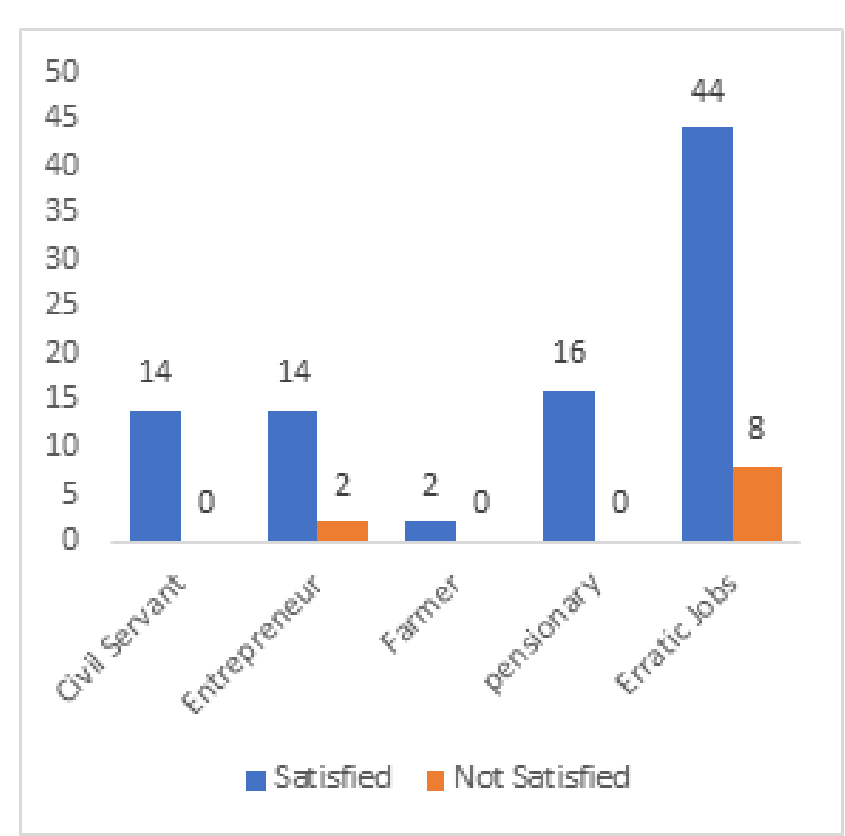

Figure 3. Percentage of satisfaction based of occupation

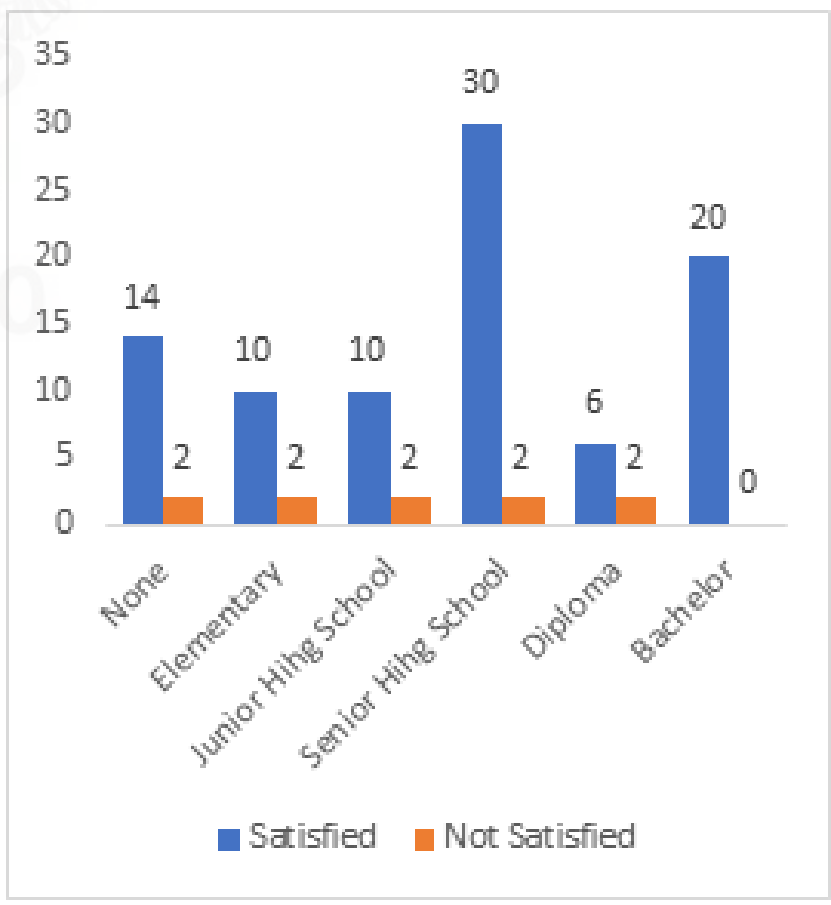

Figure 4. Percentage of satisfaction based of education level

Table 3. Comparative analysis of the level of satisfaction by gender, age, education, occupation and response time

\begin{tabular}{cccccc}
\hline $\mathrm{P}$ & Gender & Ages & \multicolumn{4}{c}{ Education Occupation } & $\begin{array}{c}\text { Response } \\
\text { Time }\end{array}$ \\
value & $0.638 \mathrm{a}$ & $0.713 \mathrm{~b}$ & $0.699 \mathrm{~b}$ & $0.614 \mathrm{~b}$ & $0.023 \mathrm{a}$ \\
\hline
\end{tabular}

$\mathrm{a}:$ chi square test, $\mathrm{b}:$ Wilcoxon test 


\section{Response Times and Patient Satisfaction in Emergency Room at Anutapura General}

Hospital, City of Palu

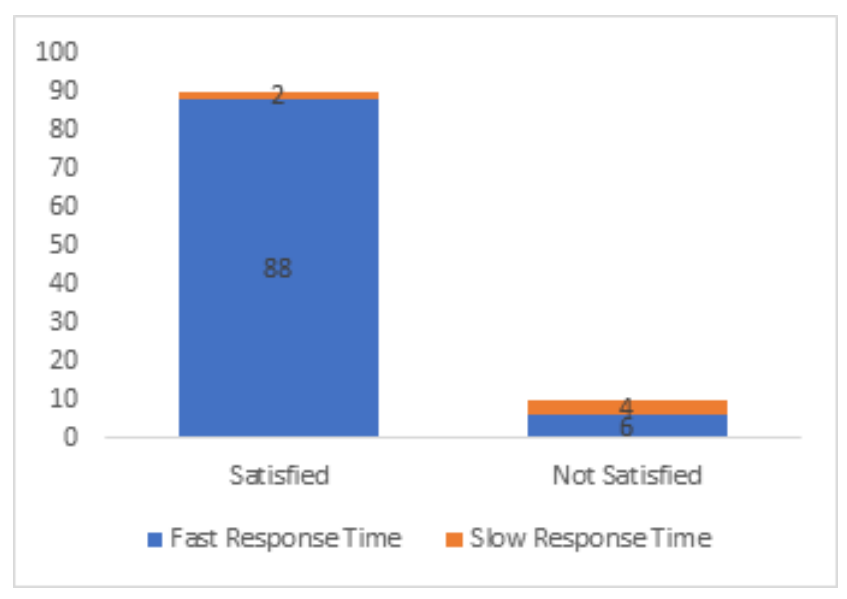

Figure 5. Level ofsatisfaction based on response time

Based on analysis Table 3 using chi square and Wilcoxon test showed that for the variables gender, ages, education and occupation there was no correlation with the level of patient satisfaction. This is evident from the value of $\mathrm{p}>$ 0.05 for all variables. As for the test on the variable level of satisfaction and response time founded association. This is evidenced by the p-value is less than the alpha (0.023> $0.05)$.

\section{DISCUSSION:}

Recently the patient satisfaction is becoming most important because it is a useful tool for assessing the quality of health services. The analysis of this study showed that for the variables gender, ages, education and occupation there was not correlation with the level of patient satisfaction. This is evident from the value of $\mathrm{p}>0.05$ for all variables. Vidhya et al stated that the results of their study based on interviews with a sample size of 440 patients, found that people with older age, married status, and low education level appraise the quality of hospital services is more higher than younger patients, unmarried and patients with higher education. [6]

The results of the doctor response time in ER of Anutapura hospital not yet $100 \%$ reached $\leq 5$ minutes following Minimum Service Standards, but the overall doctor response time here has been good, it sight by patients treated with the appropriate response time increasingly. Refers to ER Standard that the speed and accuracy in given help to patients needed accordance with the competence and ability of staff to ensure an emergency care with fast response time and precise handling. [7] It is supported by Mary in her research that suggested that the increased the patients satisfaction had a positive correlation with the identification of the correct physician and shorten the waiting time [8]

Based on researcher observations of the behavior of ER health workers in Anurapura Hospital to patient is very friendly and agile, so as give them a sense of satisfaction with the services provided. This is in line to research conducted by Eshghi et al who explained that patient satisfac- tion related to physicians education, nurses appearance, the hospital environment, ER workflow and behavior of doctors and nurses. [9] In addition, Soleimanpour et al suggest that patient satisfaction can be influenced by the clinical care process, nursing care, officers behavior, treatment of patients, the physical environment and the waiting time. [10]

Patient satisfaction is an evaluative of affective (emotional) response associated with a service quality of hospitals provided and patient expectations to these services. There are a patients who were not satisfied likely influenced by the responsiveness of health personnel both of doctors and nurses. The study conducted by Mumu et al found that there is a significant relationship between physical evidence, reliability, responsiveness, assurance, and empathy with patient satisfaction, where responsiveness is the most dominant quality dimensions in relation to patient satisfaction. [11]

Variable test results the satisfaction level of response time indicates there is a relationship. This is evidenced by the $p$ value is less than the alpha $(0.023>0.05)$. This is was supported by Kusumawinahyu et al stated that patients come to the emergency room in red and yellow triage with the total 88 respondents in each group triage, red and yellow. In bivariate data analysis, researchers used chi square test with significance level $(\alpha=0.05)$. The results obtained in the red triage group the value $\mathrm{x}^{2}=8.361$ with $p$ value of $0.015(\mathrm{p}<0.05)$, and the yellow triage group the value $\mathrm{x}^{2}$ $=9.131$ with $p$ value of $0.010(\mathrm{p}<0.05)$. Based on these results concluded that there is a relationship between the response time of emergency services on the level of patient satisfaction in red and yellow triage. [12]

Other research by Purba et al showed univariate analysis with the number of nurses fast response time $\leq 5$ minutes and $>5$ minutes each is the same namely 15 cases $(50 \%)$. Patient satisfaction is dominated are satisfied category as much as $24(80 \%)$ respondents. Based on the statistical Chi Square test $\mathrm{t}$ test then obtained value of $p=0.01 \%$. It meaning there are relationship between the response time and the level of patient satisfaction in red triage. [13]

Doctor's response time was measure using a wristwatch, this measurement begins when the patient get in the emergency room door until the doctor providing services either anamnesis or physical examination. This study particularly took samples in yellow triage category. The doctors slow response time potentially caused by the patient's arrival time almost simultaneously with another patient with red triage category, which is certainly need priority handling. The observation found response time doctors would tend to be slow if there are more than two patients admitted to the ER in the same period. This is consistent with the results of Fadhilah et al stated that the cause of the inaccuracy response time is derived from patient registration system, and the presence of other patients who come together with more serious conditions, so physicians do not alert at triage. [14]

In addition, this research using satisfaction questionnaire addressed instruments to patients and their families who accompany patients in the ER to the early arrival until has done handling by the doctor. The level of satisfaction of 
the patient's family is closely related to the services provided by the medical team in the ER. Not only speed and accuracy, but the behavior of the medical team also support in this assessment and are important in achieving the quality of nursing services in order to satisfy the service users. ${ }^{[13]}$ Research by Satrial et al, showed that there is a relationship the response time in ER facilities and handling head injury patients with $p=0.008$. The results of logistic regression analysis found that most variables have a relationship with the response time is the ER facility with OR $=6.945$, which means the ER facility has a relationship with the response time of 6.9 or 7 times more powerful than other variables related to it. ${ }^{[15]}$

Rapid memorable service delivery in the ER, besides supported by the availability of medical devices and pharmaceuticals, also required supporting infrastructure, such as patient strecher sufficient availability. General Hospital Anutapura Palu provide 4 pieces of stretcher is placed at the front door of the emergency room, the beds are 28 pieces with a composition of 3 beds for triage, 2 special bed resuscitation, 4 beds to a room surgery, 2 beds to a room inhalation and rest for observation.

The important strategy that should be considering in order to meet of the standard of response time is to do with the fulfillment of the facilities and infrastructure that support the delivery of care to patients. Tools and consumable medical supplies is one of the components needed to manage patients. The patients handling will be hampered if both of it not available and could adversely affect the patient's condition. This availability is influence with several factors, such as hospital management planning system and the availability in ER pharmacies. General Hospital Anutapura have a special pharmacies in ER which may facilitate patient or patient's family in redeeming the drug so as to accelerate the handling of patients. This is in accordance with the opinion expressed by Naser et al that the availability of equipment and medicine when needed greatly affect the response time in handling emergency patients. [16]

In addition, the availability of easily accessible strecher can affect response time. This is consistent with Sabriyat et al, that the are internal and external factors affecting the delay of handling emergency cases, namely the availability of stretcher and triage officers, with results of the study there a significant relationship between the availability of triage officers with the timeliness of response handling cases in ER Surgical ( $p=0.006$; PR $=2.97$ ), and there is a significant correlation between the availability of stretcher with response time to handling cases in ER Surgical $(p=0.006 ; \mathrm{PR}=9.217)$ and Non-Surgical ( $p=$ $0.026 ; \mathrm{PR}=1.995)$. [17]Response time is extremely important in dealing with emergency patients, especially patients with red and yellow triage category because it can reduce the breadth of damage to the internal organs. Complacency can arise when getting fast service either the patient or the their family is also supported by empathy, friendliness, and good communication between the families of patients with health care providers, especially physicians. It is appropriate with Khankeh et al stated that the response time in the
ER is a major problem that causes patient dissatisfaction indirectly and can lead to increased patient morbidity. The use of triage can significantly shorten the waiting time and increase patient satisfaction. [18]

The quality of medical services provided greatly affect the level of patient satisfaction. It is one important part of the performance of the health system in the hospital and should be evaluating regularly. In a study by Besciu showed that increased patient satisfaction correlated with physicians who have the experience, ability to handle emergency patients quickly and accurately. Additionally, if patients were satisfied with the service, then they are would have recommend the hospital with the possibility of doing word of mouth and indirectly establish patient loyalty for readmission to the hospital. $[19,20]$

\section{CONCLUSION:}

In this study, there is a relationship between response time doctor with patient satisfaction at ER Anutapura Hospital Palu with $p$ value $=0.001$. The response time is extremely important in the treatment of emergency patients and will affect the quality of life and patient satisfaction, including decrease of mortality and morbidity incidence in the ER.

\section{Suggestion:}

1. Improving response time doctors in the provision of services to patients in order to create patient satisfaction with hospital services.

2. Conducting further research on the analysis of a factors that can affect the response time doctor to the satisfaction of the patient's in the hospital, especially in the ER.

Conflict of Interest: The authors declare no potential conflict of interest in this article publish

Acknowledgment: The authors sincerely thank to all people who have contributions and supports this research, especially the head of Anutapura General Hospital.

\section{REFERENCES}

[1] Mutiarasari D, T PR, Gunadi. Evaluation of the Development Process and Application of Acute Ischemic Stroke Clinical Pathway Cases in Anutapura Hospital, Palu City. Scientific Period of Medical Duta Discourse; 2017.

[2] President of the Republic of Indonesia. Law of the Republic of Indonesia Number: 44 of 2009 concerning Hospitals; 2009.

[3] Relationship between nurse response time and patient's family confidence level in yellow triage (urgent) in the Emergency Installation of. GMIM Hospital Kalooran Amurang. $2015 ; 3(2)$.

[4] The relationship between the accuracy of the implementation of triage and the level of family satisfaction of patients in the Emergency Room of RSUP Prof. Dr R D Kandou Manado. 2017;5(1).

[5] Minimum hospital standard of service. Decree of the Minister of Health of the Republic of Indonesia Number. 2008;

[6] Vidhya K, Rajkumar CS. An empirical study on perceived service quality and patient satisfaction with reference to Puduchcheri Hospitals. Asia Pac J Res I. 2014;(XIV),:189196. 


\section{Response Times and Patient Satisfaction in Emergency Room at Anutapura General Hospital, City of Palu

[7] Standard of Hospital Emergency Installation. Decree of the Minister of Health of the Republic of Indonesia Number. $2009 ; 856$.

[8] Physician Identification and Patient Satisfaction in the Emergency Department: Are They. Mary;

[9] Eshghi M, Rahmani F, Derakhti B, Robai N, Abdollahi F, Tajoddini S. Patient satisfaction in emergency department: a case of Sina hospital in Tabriz. Journal of Emergency Practice and Trauma. 2016;2(1).

[10] Emergency patient satisfaction survey in Imam Reza Hospital. Tabriz, Iran International Journal of Emergency Medicine. 2011;4(2).

[11] Mumu LJ, Grace DK, Diana VD. Analysis of factors related to patient satisfaction at the. Internal Medicine Polyclinic of RSUP Prof Dr R D Kandou Manado. 2015;5(4).

[12] Kusumawinahyu DS, Purwanti OS, Kartinah. The relationship of the response time of emergency department services to the level of patient satisfaction; 2016. at Surakarta Islamic Hospital.

[13] Relationship between response time and family satisfaction of emergency patients in red triage at the emergency room at RSUP Prof. Dr R D Kandou Manado. 2015;3(2).

[14] Factors related to response time in the service of traffic accident cases in the Emergency Installation of Dr.M.Jamil Padang Hospital in. Andalas Health Journal. 2015;4(1):195201.

[15] Related factors of head injury response time in emergency unit of Prof. Journal of Indonesian Contemporary Nursing Journal. 2018;2(1):1-12.

[16] The relationship of external factors with the response time of nurses in the handling of emergency patients at the ER RSUP PROF. DR R D Kandou Manado. 2015;3(2).

[17] Factors related to the timely response to case handling in response time in the Surgical and Non-Surgical Emergency Installation of RSUP. DR. Wahidin Sudirohusodo; 2012.

[18] Example from Iran: Example from Iran. Iranian Journal of Nursing and Midwifery Research. 2013;18(1):79-83.

[19] Beşciu CD. Patient Satisfaction in the Hospital's Emergency Units in Bucharest. Procedia Economics and Finance; 2015.

[20] Managing patient expectations at emergency department triage. Patient Experience Journal. 2015;2(2):31-44. 